\title{
Expression of bacterial virulence factors and cytokines during in vitro macrophage infection by enteroinvasive Escherichia coli and Shigella flexneri: a comparative study
}

\author{
Silvia Y Bando ${ }^{1,2}$, Ana CR Moreno', José AT Albuquerque', Juliana MK Amhaz", \\ Carlos A Moreira-Filho², Marina B Martinez ${ }^{1 /+}$ \\ 'Departamento de Análises Clínicas e Toxicológicas, Faculdade de Ciências Farmacêuticas ²Departamento de Pediatria, \\ Faculdade de Medicina, Universidade de São Paulo, Av. Prof. Lineu Prestes 580, 05508-000 São Paulo, SP, Brasil
}

Enteroinvasive Escherichia coli (EIEC) and Shigella spp cause bacillary dysentery in humans by invading and multiplying within epithelial cells of the colonic mucosa. Although EIEC and Shigella share many genetic and biochemical similarities, the illness caused by Shigella is more severe. Thus, genomic and structure-function molecular studies on the biological interactions of these invasive enterobacteria with eukaryotic cells have focused on Shigella rather than EIEC. Here we comparatively studied the interactions of EIEC and of Shigella flexneri with cultured J774 macrophage-like cells. We evaluated several phenotypes: (i) bacterial escape from macrophages after phagocytosis, (ii) macrophage death induced by EIEC and S. flexneri, (iii) macrophage cytokine expression in response to infection and (iv) expression of plasmidial (pINV) virulence genes. The results showed that $\mathrm{S}$. flexneri caused macrophage killing earlier and more intensely than EIEC. Both pathogens induced significant macrophage production of TNF, IL-1 and IL-10 after $7 \mathrm{~h}$ of infection. Transcription levels of the gene invasion plasmid antigen-C were lower in EIEC than in $\mathrm{S}$. flexneri throughout the course of the infection; this could explain the diminished virulence of EIEC compared to $\mathrm{S}$. flexneri.

Key words: EIEC - Shigella - in vitro infection - cytokines - virulence factors

Infectious diarrhea is one of the main causes of childhood death, especially in developing countries (Bryce et al. 2005) and Escherichia coli is a major diarrhea-causing pathogen in children under five years of age (Petri et al. 2008, Moreno et al. 2010). E. coli isolated from patients with dysentery was found to cause experimental keratoconjunctivitis in guinea pigs in the early 1960s (Trabulsi et al. 1967, DuPont et al. 1971). These strains, thereafter named enteroinvasive $E$. coli (EIEC), possess genetic and biochemical characteristics similar to Shigella (Silva et al. 1980, Sansonetti et al. 1982, Kaper et al. 2004).

EIEC and Shigella cause bacillary dysentery in humans by invading and multiplying within epithelial cells of the colonic mucosa, resulting in an intense inflammatory response characterized by abscesses and ulcerations (Hale 1998, Parsot et al. 2005). The genes required for bacterial entrance into host cells are harboured in a 230$\mathrm{kb}$ virulence plasmid (VP) present in Shigella and EIEC strains (Harris et al. 1982, Sansonetti et al. 1982, Silva et al. 1982). Transcription of invasion plasmid antigen (ipa) genes is regulated by two VP-encoded proteins:

Financial support: FAPESP (203/01269-1)

ACRM and JMKA received PhD fellowships from CAPES and FAPESP, respectively. SYB received a post-doctoral fellowship from CNPq. JATA was a MSc fellow from CNPq. CAM-F is a research fellow from CNPq.

+ Corresponding author: mbmartin@usp.br

Received 20 January 2010

Accepted 7 June 2010
VirF and VirB (Dorman et al. 2001). VirB also controls transcription of the VP genes that code for the proteins of the type three secretion system (TTSS) apparatus. Intracellular movement (ics) A and icsB play a crucial role in bacterial dissemination: the first leads to bacterial invasion and intracellular spreading and the latter aids in escape from autophagy.

Shigella translocates through $\mathrm{M}$ cells of the intestinal epithelium to invade the epithelial layer by the basolateral pole (Sansonetti 1991, Ménard et al. 1996, Sansonetti et al. 1996). Shigella can survive and multiply inside macrophages, escape from phagocytic vacuoles and induce apoptosis (Sansonetti et al. 1986, Zychlinsky et al. 1992, 1996, Nonaka et al. 2003, Kubota 2006). Apoptosis of infected macrophages is promoted by caspase-1 activation. Caspase-1 cleaves the IL-1 and IL-18 precursors to their mature forms, triggering a mucosal inflammatory response (Navarre \& Zychlinsky 2000, Kubota 2006, Suzuki et al. 2007).

An inoculum of $10^{2}$ Shigella cells is sufficient for infection, but as many as $10^{6}$ EIEC cells are necessary (DuPont et al. 1971), indicating the diminished virulence of EIEC. The cellular processes and genes related to bacterial invasion have been investigated primarily in Shigella flexneri and thus remain poorly understood in EIEC. The interaction of EIEC with macrophage is relevant because bacterial survival inside phagosomes and the subsequent escape from macrophages are critical steps for the establishment of an infection. Therefore, the aim of this study was to compare the expression of genes involved in the regulation of virulence factor production $(v i r \mathrm{~F}$ and $v i r \mathrm{~B})$ and cell lysis $(i p a \mathrm{~B}, i p a \mathrm{C})$ as well 
as spreading and ics $\mathrm{A}$ and $i c s \mathrm{~B}$. We also measured the cytokine response upon in vitro infection of macrophages with EIEC or S. flexneri.

\section{SUBJECTS, MATERIALS AND METHODS}

Bacterial strains - The M90T strain (invasive S. flexneri 5a) was kindly donated by Philip Sansonetti (Pasteur Institute). EIEC strain FBC124-13, serotype O124: $\mathrm{H}^{-}$, was isolated from diarrheic faeces and was Sereny testpositive (Gibotti et al. 2004). Bacteria were grown at $37^{\circ} \mathrm{C}$ for two days on trypticase soy agar plates containing $0.02 \%$ Congo Red. Prior to cell infection, a single red colony of each strain was inoculated in trypticase soy broth and grown at $37^{\circ} \mathrm{C}$ with agitation $(150 \mathrm{rpm})$ to an $\mathrm{OD}_{625}$ of 0.1 , which corresponds to $1 \times 10^{8}$ colony forming units $(\mathrm{CFU}) / \mathrm{mL}$.

Cell culture and macrophage infection - The J774 macrophage-like cells were maintained in Roswell Park Memorial Institute (RPMI) 1640 medium supplemented with $10 \%$ fetal bovine serum (FBS) and penicillin-streptomycin $(100 \mathrm{u} / \mathrm{mL}-100 \mu \mathrm{g} / \mathrm{mL})$ in a $5 \% \mathrm{CO}_{2}$ incubator at $37^{\circ} \mathrm{C}$. Twenty-four hours prior to infection macrophages were plated in 24 -well plates at a density of $1 \times 10^{6}$ cells per well. The medium was then replaced by fresh RPMI 1640 containing $10 \%$ FBS (without antibiotics) and the macrophages were infected with a multiplicity of infection (MOI) of 10 bacteria per cell, centrifuged at $100 \mathrm{~g}$ for $5 \mathrm{~min}$ and incubated for different periods of time.

Bacterial survival inside the macrophages - Macrophages were infected with $S$. flexneri or EIEC for zero (cells harvested just after bacterial inoculation), 30, 60 and $90 \mathrm{~min}$. The cells were then incubated with medium containing $50 \mu \mathrm{g} / \mathrm{mL}$ gentamicin for 50 min to kill nonphagocytosed bacteria and to prevent reinfection. The infected macrophages were washed three times with PBS. PBS containing $0.1 \%$ Triton X-100 was then added to each well to lyse the macrophages. The recovered bacteria were resuspended in $0.9 \% \mathrm{NaCl}$, serial dilutions were plated on MacConkey agar and the CFU were counted following an overnight incubation of the plates at $37^{\circ} \mathrm{C}$.

Bacterial escape and macrophage death - To assess bacterial escape after phagocytosis and determine whether this process was accompanied by macrophage death, J774 cells were infected for an hour with EIEC or $S$. flexneri and then the medium was replaced by fresh RPMI 1640 containing $10 \%$ FBS and $50 \mu \mathrm{g} / \mathrm{mL}$ of gentamicin. Following different periods of post-infection incubation $(30,60$ or $90 \mathrm{~min})$ in medium without antibiotic, supernatant dilutions were plated to determine the CFU. The macrophages were then resuspended in a hypotonic fluorochrome solution $(0.1 \%$ sodium citrate, $0.1 \%$ Triton X-100 and $50 \mu \mathrm{g} / \mathrm{mL}$ of propidium iodide) and analyzed on a FACScalibur flow cytometer (Becton Dickinson, Mountain View, CA, USA).

Detection of cytokines by enzyme-linked immunosorbent assay (ELISA) - The J774 macrophages were infected as described for the bacterial escape assay, however with an MOI of 1:10. After one hour of infection, the medium was replaced by fresh RPMI 1640 containing
$10 \%$ FBS and $50 \mu \mathrm{g} / \mathrm{mL}$ of gentamicin. Supernatants of post-infected J774 cell cultures were collected after $6 \mathrm{~h}$ of incubation. Concentrations of IL-1, TNF and IL-10 were determined by ELISA according to the manufacturer's instructions (Peprotech, Mexico).

Expression of EIEC and S. flexneri virulence genes in infected macrophages - Total RNA from infected macrophages was extracted with a RNeasy Mini Kit (Qiagen, Hilden, Germany), as described by the manufacturer. Contaminating genomic DNA was removed using the RNase-free DNase Data Set (Qiagen, Hilden, Germany) and samples were frozen at $-80^{\circ} \mathrm{C}$ until use. Total RNA was quantified by A260 measurements (NanoDrop ${ }^{\circledR}$ ND1000 Spectrophotometer; Amersham Biosciences) and diluted to $10 \mathrm{ng} / \mu \mathrm{L}$ prior to cDNA synthesis. Bacterial mRNA was reverse transcribed into cDNA using the Superscript II First-Strand Synthesis System with random hexamers, as described by the manufacturer (Invitrogen, Carlsbad, CA, USA). The cDNA was sequenced to check the primer and probe adequacy. Reverse transcriptase polymerase chain reaction (RT-PCR) products were obtained by PCR amplification for 30 cycles as follows: $95^{\circ} \mathrm{C}$ for $45 \mathrm{~s}, 50-60^{\circ} \mathrm{C}$ (Table I) for $45 \mathrm{~s}$ and $72^{\circ} \mathrm{C}$ for $2 \mathrm{~min}$, with an initial denaturation step of $95^{\circ} \mathrm{C}$ for $5 \mathrm{~min}$ and final extension step of $72^{\circ} \mathrm{C}$ for $7 \mathrm{~min}$. The virulence genes studied here and their respective primers are listed in Table I.

Quantitative real-time PCR (qRT-PCR) analyses were carried out using a TaqMan assay on an ABI Prism 7000 Sequence Detection System version 1.6 (Applied Biosystems). The parameters for PCR were as follows: $50^{\circ} \mathrm{C}$ for $2 \mathrm{~min}, 95^{\circ} \mathrm{C}$ for $10 \mathrm{~min}$ and 50 cycles of $95^{\circ} \mathrm{C}$ for $15 \mathrm{~s}$ and $60^{\circ} \mathrm{C}$ for $1 \mathrm{~min}$. The primers and the fluorogenic probes (Assays-by-design, Applied Biosystems) used in this study are described in Table II. For each reaction, 16S rRNA was used as an endogenous housekeeping gene control. Data were normalized to control levels and analyzed by the standard curve method. The relative comparison method was used to evaluate the expression levels of the bacterial virulence genes.

Statistical analysis - The data were analyzed by a two way analysis of variance and the results were confirmed through multiple comparisons by Tukey's test. Differences between groups were considered significant when $\mathrm{p}<0.05$.

\section{RESULTS}

Survival and escape of EIEC and S. flexneri during infection of J774 macrophages - The number of viable intracellular EIEC was higher than S. flexneri after 30 and $60 \mathrm{~min}$ of infection (Fig. 1A). The amount of bacteria recovered from supernatants confirmed a diminished capacity of EIEC to escape from macrophages. After 30 or $60 \mathrm{~min}$ of incubation in gentamicin-free medium, macrophage cultures infected with S. flexneri yielded 4-fold higher CFU in comparison with those infected with EIEC (Fig. 1B). To confirm that these differences were due to escape from macrophages and not to differences in bacterial multiplication rate, growth curves for EIEC and S. flexneri in LB media were obtained and found to be very similar (data not shown). 
TABLE I

Virulence genes and respective primers used for quantitative reverse transcriptase polymerase chain reaction

\begin{tabular}{|c|c|c|c|}
\hline Gene & Primer sequence (5'-3') & $\begin{array}{l}\text { Fragment size } \\
\qquad(\mathrm{bp})\end{array}$ & $\begin{array}{l}\text { Hybridization temperature } \\
\qquad\left({ }^{\circ} \mathrm{C}\right)\end{array}$ \\
\hline ipaB & $\begin{array}{l}\text { IpaB-F CCGGCAATTCCTTCATGGAAC } \\
\text { IpaB-R AGTTGAGAAGAAAAATTCTTG }\end{array}$ & 310 & 50 \\
\hline ipaC & $\begin{array}{l}\text { IpaC-F GTCACACAAGTAGGTATAACG } \\
\text { IpaC-R TCTGGGTGTCAATTTTATCCT }\end{array}$ & 301 & 50 \\
\hline$i c s A$ & $\begin{array}{l}\text { IcsA-F GAGTCAATCTACCCATAATC } \\
\text { IcsA-R GTGTTCCATCATCTTGTTTAC }\end{array}$ & 342 & 50 \\
\hline$i c s B$ & $\begin{array}{l}\text { IcsB-F TGCATCAAGTCTTTCGGCTGT } \\
\text { IcsB-R AACTCAATTCAACACTCTTTC }\end{array}$ & 355 & 55 \\
\hline $\operatorname{virF}$ & $\begin{array}{l}\text { VirF-F CATTTCAACACTCCTATTC } \\
\text { VirF-R AACTAAGAGAAGAAGCTATCG }\end{array}$ & 208 & 53 \\
\hline $\operatorname{vir} B$ & $\begin{array}{l}\text { VirB-F CAGCAAAAGAGCATAGCATC } \\
\text { VirB-R AGAGATTCATTAGCCTTTTC }\end{array}$ & 251 & 53 \\
\hline $16 S$ & $\begin{array}{l}\text { 16S-F CAGCAGCCGCGGTAATAC } \\
\text { 16S-R ACCAGGGTATCTAATCCTGT }\end{array}$ & 283 & 60 \\
\hline
\end{tabular}

the primers were designed based on the known sequences of Shigella flexneri (Venkatesan et al. 2001). ics: intracellular movement; ipa: invasion plasmid antigen; vir: virulence factor production.

TABLE II

Primers and probes used for quantitative reverse transcriptase polymerase chain reaction

\begin{tabular}{lccc}
\hline Gene & Primer 5' (5'-3') & Probe (5'FAM) & Primer 3' (5'-3') \\
\hline$i p a B$ & TTGGGCGTCGACTCGAAAA & ATTGCCCCCAGAATAGA & ACTGCTGCAACTAGGACAAGAG \\
$i p a C$ & CCTCACCACAAACTAACTCTAGCA & CTGGCGCCAGTTTAT & GAGAAGTTTTATGTTCAGTT- \\
& & & GACAGGGATA \\
$i c s A$ & CTCTCTGTAATCAATAAGGGCACGTT & CCGTAAGCAGCACCTCC & CCACCGTAGCCATCATAACCATAA \\
$i c s B$ & CATTCCGCCGGGATACCA & CTACAGGAACCAACTCATACCT GGCATAACCCATTTAGGGCATACTA \\
virF & TCTGAGGAGGAGGTTTCTATCGATT & CCGAAAGGCATCTCTTT & GAAACAGCTGATAAAAGGCAAGCT \\
virB & TCTCGCGCGAAAGTCACT & CCTTTCAGGCAGCAAGC & GTTCTGACGCGATTGGAAATAGAGA \\
$16 S$ & GCGGTTTTTAAGTCAGATGTGAAA & TCAACCTGGGAACTGC & GACTCAAGCTTGCCAGTATCAGAT
\end{tabular}

ics: intracellular movement; ipa: invasion plasmid antigen; vir: virulence factor production.
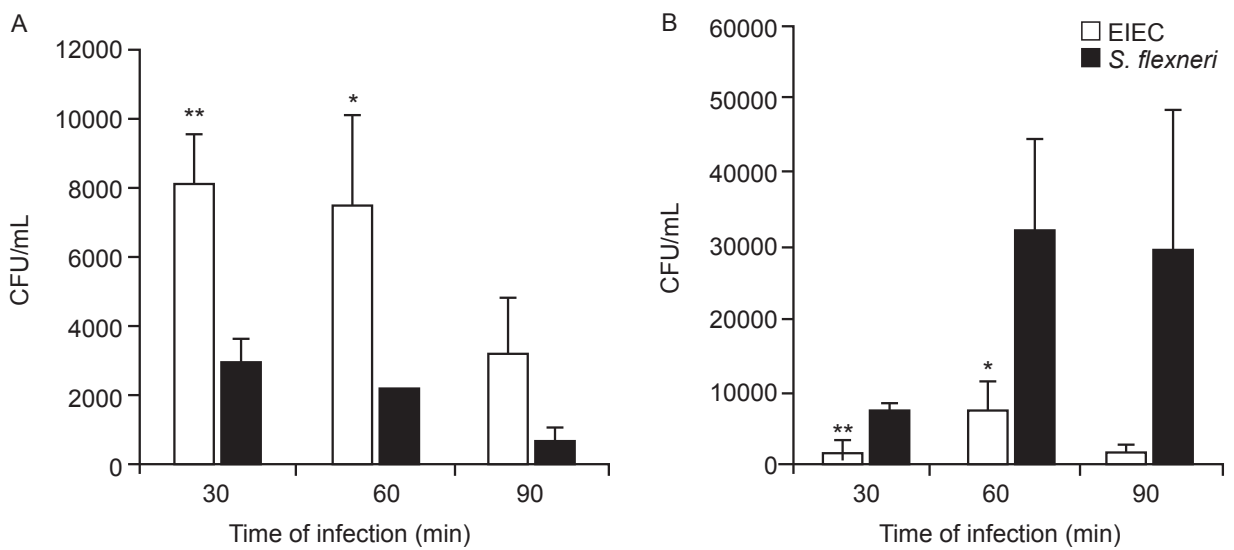

Fig. 1: colony forming units (CFU) values measured inside cultured cells (A) and in culture supernatant (B) for enteroinvasive Escherichia coli (EIEC) (white bar) and Shigella flexneri (black bar) after phagocytosis by J774 macrophages. CFU values were determined in triplicates in two independent experiments. Statistical analysis was performed by two-way analysis of variance. $\mathrm{p}$ values of less than 0.05 were considered as statistically significant. $*$ : $\mathrm{p}<0.05 ; * * \mathrm{p}<0.01$. 
J774 cells death caused by bacterial infection - Macrophage death rates due to $S$. flexneri and EIEC infections were analyzed throughout $8 \mathrm{~h}$ of infection (Fig. 2). We observed $50 \%$ cell death in cultures infected with $S$. flexneri at $2 \mathrm{~h}$ post-infection, whereas in EIEC infected cultures we observed only $20 \%$ cell death. This difference was proportionally maintained until the 4 th $\mathrm{h}$ of infection and convergence of cell death ratios was observed after $8 \mathrm{~h}$ of infection, indicating that EIEC is less efficient than $S$. flexneri at macrophage killing.

Cytokines expression after J774 infection with EIEC and $S$. flexneri - We determined the expression levels of IL-1, IL-10 and TNF- $\alpha$ following infection of J774 macrophages with EIEC or S. flexneri to evaluate if the cytokine expression profile differs based on the infecting bacterial species. We observed a similar increase in IL-1, IL-10 and TNF concentrations measured in the supernatants of J774 cells infected with EIEC or S. flexneri compared to supernatants from uninfected cultures (Fig. 3).

Differential expression of selected virulence genes in EIEC and S. flexneri during J774 cell infection - qRTPCR was performed to measure $\operatorname{virF}$, virB, ipaB, ipaC, $i \operatorname{cs} A$ and $i c s B$ transcription rates every 30 min during the 1 st $2 \mathrm{~h}$ of infection. We observed a very low ipa $\mathrm{C}$ transcription level in EIEC, but not in S. flexneri, throughout the course of the infection (Fig. 4). This was the only statistically significant difference between EIEC and $S$. flexneri virulence gene expression at all time intervals. Higher transcription levels were also observed for $\operatorname{vir} B$ and ics $A$ in $S$. flexneri during the initial $30 \mathrm{~min}$ and during the 30-60 min interval, respectively. Transcription of $i c s B$ was elevated in S. flexneri at 90 min after infection. No significant differences between EIEC and S. flexneri were found in the transcription levels of $\operatorname{virF}$ and $i p a B$ (data not shown). The expression of EIEC or S. flexneri virulence genes was also studied when bacteria were cultured in medium without contact with $\mathrm{J} 774$ cells and we observed no difference in gene expression between EIEC and S. flexneri (data not shown).

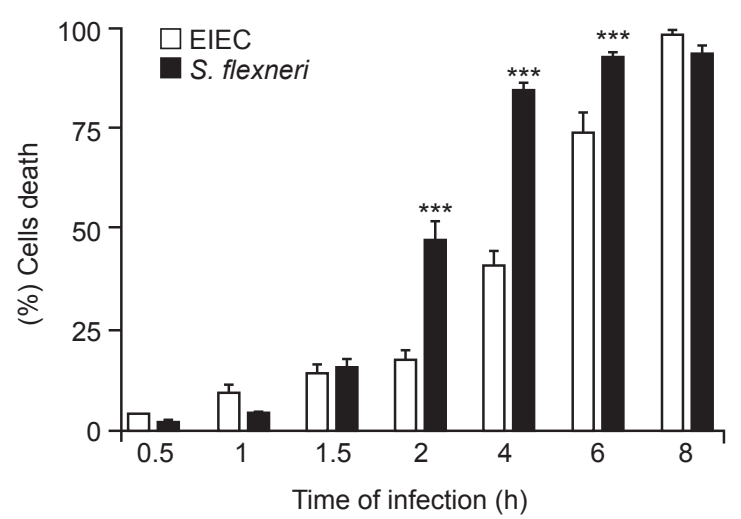

Fig. 2: J774 cell death ratios caused by enteroinvasive Escherichia coli (EIEC) (white bar) or Shigella flexneri (black bar) were determined on a FACScalibur flow cytometer. Statistical analysis was performed by two-way analysis of variance. $p$ values of less than 0.05 were considered as statistically significant. Asterisks mean $\mathrm{p}<0.001$.

\section{DISCUSSION}

Shigella pathogenicity is determined by several genes encoded by the VP promoting bacterial invasion, escape and proliferation across enterocytes. However, this mechanism remains to be fully elucidated for EIEC. In this work, we aimed to clarify differences between EIEC and $S$. flexneri regarding macrophage escape mechanisms, expression of associated virulence genes and the macrophage cytokine expression profile induced by these bacteria.
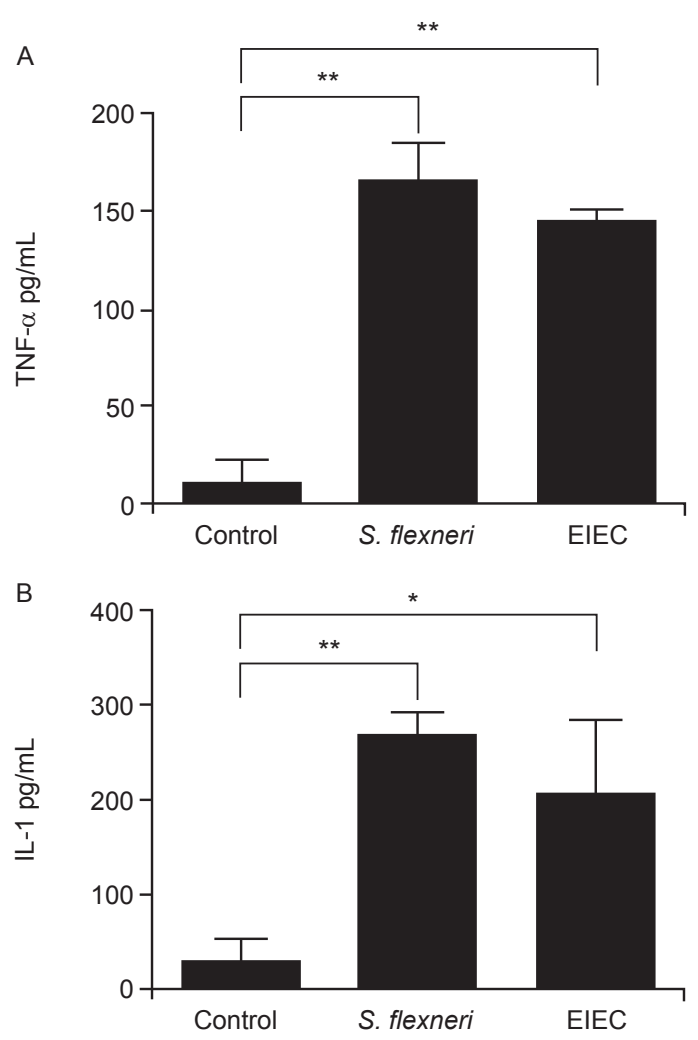

C

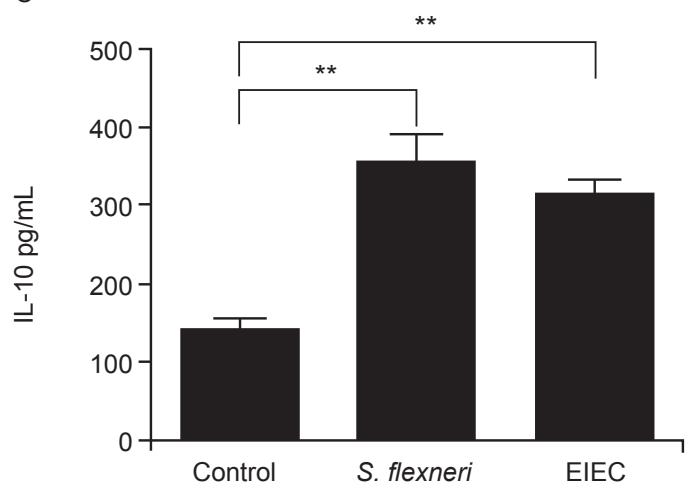

Fig. 3: production of TNF (A), IL-1 (B) and IL-10 (C) by J774 macrophages infected with enteroinvasive Escherichia coli (EIEC) or Shigella flexneri at $6 \mathrm{~h}$ post-infection: data is presented as mean and standard deviation from quaduplicate infections in two independent experiments. Statistical analysis was performed by two-way analysis of variance. $p$ values of less than 0.05 were considered as statistically significant. *: $\mathrm{p}<0.05 ; * *: \mathrm{p}<0.01$. 

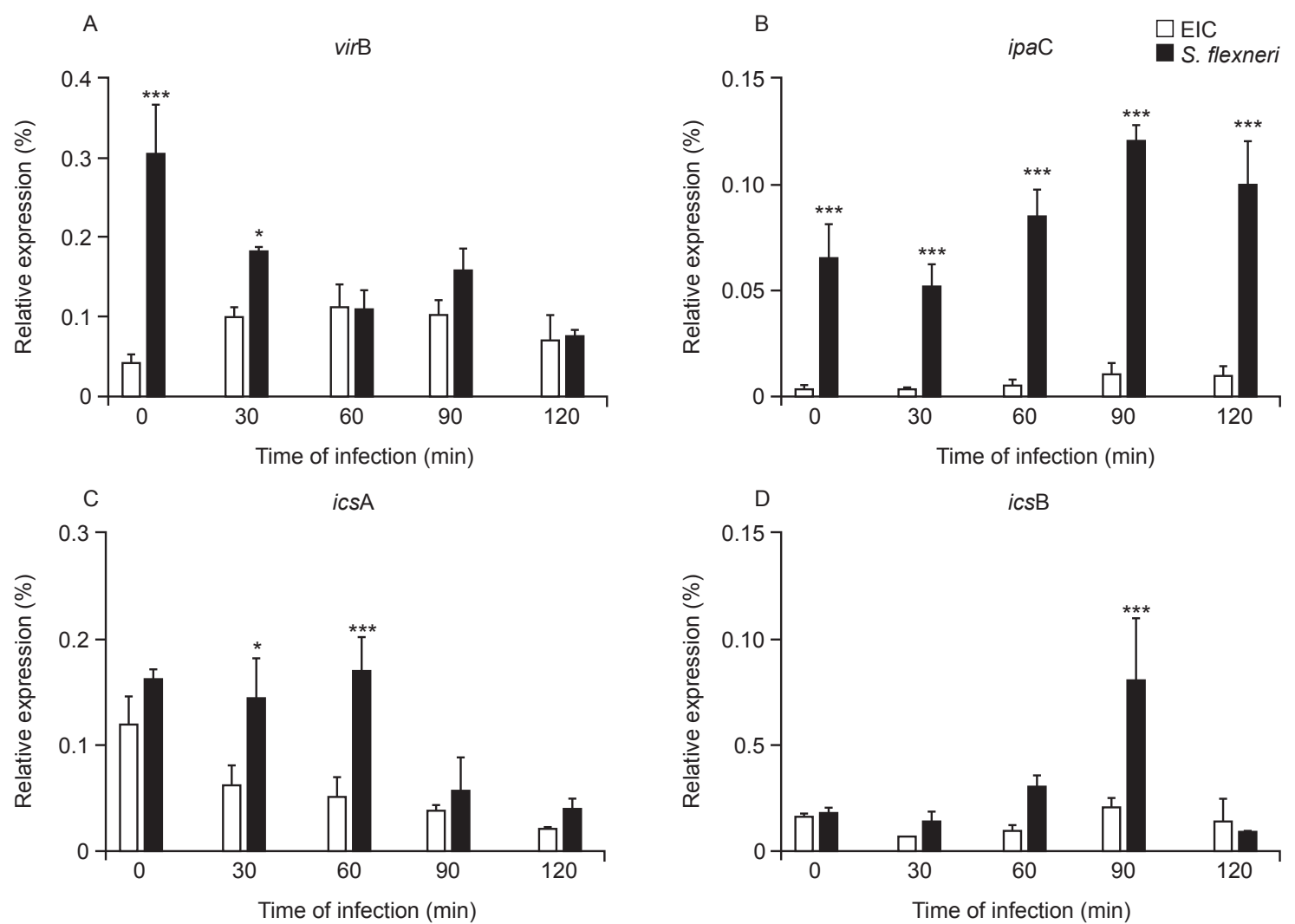

Fig. 4: transcriptional profiles of virulence factor production (vir) B (A), invasion plasmid antigen (ipa) C (B), intracellular movement (ics) A (C) and icsB (D) genes of enteroinvasive Escherichia coli (EIEC) (white bar) or Shigella flexneri (black bar) obtained by quantitative real-time polymerase chain reaction during different periods of infection in J774 macrophages. Results are presented as mean and standard deviation from triplicate experiments. Statistical analysis was performed by two-way analysis of variance. $p$ values of less than 0.05 were considered as statistically significant. *: $\mathrm{p}<0.05 ; * * \mathrm{p}<0.01 ; * * * \mathrm{p}<0.001$.

Infection with $S$. flexneri causes rapid macrophage death (Clerc et al. 1987, Nonaka et al. 2003), which constitutes an evasion mechanism from the innate immune system (Kubota 2006, Schroeder \& Hilbi 2008). Therefore, the first step in the present investigation consisted of determining whether EIEC and S. flexneri survive in and escape from macrophages in a similar way. EIEC was less efficient in macrophage killing during the initial $4 \mathrm{~h}$ of infection than S. flexneri (Figs 1,2) which may indicate differences in the expression of virulence genes.

The virulence gene ipa $\mathrm{C}$ is involved in bacterial escape from the phagocytic vacuole and is responsible for lysis of the phagosome membrane (Harrington et al. 2006, Schroeder \& Hilbi 2008). This gene is also responsible for human epithelial cell invasion by targeting the TTSS, which leads to the efficient injection of effector proteins that improve the invasion process (Jaumouillé et al. 2008). In the present study, we detected a very low expression of ipa $\mathrm{C}$ in EIEC throughout the infection compared to $S$. flexneri (Fig. 4). EIEC shares almost complete identity of the ipaC nucleotide sequence with $S$. flexneri (Gibotti et al. 2004), suggesting that an EIEC chromosomal factor(s) could modulate ipa $\mathrm{C}$ transcription inside macrophages. However, further studies are necessary to investigate this hypothesis. No differences in the expression of the proapoptotic gene ipaB were detected between EIEC and $S$. flexneri. This gene encodes for a protein that activates caspase-1, which initiates macrophage apoptosis and the cleavage of proinflammatory cytokines (Zychlinsky et al. 1994, Schroeder \& Hilbi 2008).

Recently, we studied the expression of EIEC and $S$. flexneri VP genes in a different experimental model, focusing on intestinal cell invasion and dissemination. We demonstrated that the disease triggered by EIEC may be restricted to a definite infection site, meaning that it is not capable of disseminating beyond a certain point to extend and worsen tissue injury as Shigella does. This phenomenon may be associated with the lower level of virulence factor expression in EIEC when compared to Shigella (Moreno et al. 2009). However, the lower pathogenicity of EIEC could also be related to the host inflammatory response against these bacteria.

In addition to studying the expression of VP virulence genes of EIEC and Shigella after internalization into macrophages, we also investigated how macrophages responded to infection by these pathogens. No significant cytokine expression differences were observed in J744 macrophages infected with EIEC or S. flexneri. A comparable elevation in the expression of IL-1, IL-10 and TNF- $\alpha$ was detected in culture supernatants $6 \mathrm{~h}$ post-infection with both species. This result is in agreement with the similar expression of $i p a \mathrm{~B}$ in EIEC and S. flexneri. 
In conclusion, EIEC demonstrates a delayed killing effect in J774 macrophage cultures when compared to $S$. flexneri. This in vitro behavior was found to be related to the diminished ipa $\mathrm{C}$ expression. Therefore, EIEC's "slow invasion" of colonic epithelial cells in vivo could be related to the hypoexpression of $i p a \mathrm{C}$, leading to a prolonged presence inside infected cells. All together, these data could explain why EIEC takes longer than Shigella species to cause diarrhea. We believe that more experiments with host cells should be conducted to better understand the inflammatory response generated by EIEC.

\section{ACKNOWLEDGEMENTS}

To Dr Patrícia Tobo, for help with real-time PCR analysis.

\section{REFERENCES}

Bryce J, Boschi-Pinto C, Shibuya K, Black RE, WHO Child Health Epidemiology Reference Group 2005. WHO estimates of the causes of death in children. Lancet 365: 1147-1152.

Clerc PL, Ryter A, Mounier J, Sansonetti PJ 1987. Plasmid-mediated early killing of eucaryotic cells by Shigella flexneri as studied by infection of J774 macrophages. Infect Immun 55: 521-527.

Dorman CJ, McKenna S, Beloin C 2001. Regulation of virulence gene expression in Shigella flexneri, a facultative intracellular pathogen. Int J Med Microbiol 291: 89-96.

DuPont HL, Formal SB, Hornick RB, Snyder MJ, Libonati JP, Sheahan DG, LaBrec EH, Kalas JP 1971. Pathogenesis of Escherichia coli diarrhea. N Engl J Med 285: 1-9.

Gibotti A, Tanaka TL, Oliveira VR, Taddei CR, Martinez MB 2004. Molecular characterization of enteroinvasive Escherichia coli ipa genes by PCR-RFLP analysis. Braz J Microbiol 35: 74-80.

Hale TL 1998. Bacillary dysentery. In WJ Hansler, M Shuman, Topley and Wilson's microbiology and microbial infections, Arnold, London, p. 479-493.

Harrington A, Darboe N, Kenjale R, Picking WL, Middaugh CR, Birket S, Picking WD 2006. Characterization of the interaction of single tryptophan containing mutants of IpaC from Shigella flexneri with phospholipid membranes. Biochemistry 45: 626-636.

Harris JR, Wachsmuth IK, Davis BR, Cohen ML 1982. High-molecular-weight plasmid correlates with Escherichia coli enteroinvasiveness. Infect Immun 37: 1295-1298.

Jaumouillé V, Francetic O, Sansonetti PJ, Tran Van Nhieu T 2008. Cytoplasmic targeting of IpaC to the bacterial pole directs polar type III secretion in Shigella. EMBO J 27: 447-457.

Kaper JB, Nataro JP, Mobley HL 2004. Pathogenic Escherichia coli. Nat Rev Microbiol 2: 123-140.

Kubota K 2006. A novel functional T cell hybridoma recognizes macrophage cell death induced by bacteria: a possible role for innate lymphocytes in bacterial infection. J Immunol 176: 7576-7588.

Ménard R, Dehio C, Sansonetti PJ 1996. Bacterial entry into epithelial cells: the paradigm of Shigella. Trends Microbiol 4: 220-226.

Moreno AC, Ferreira LG, Martinez MB 2009. Enteroinvasive Escherichia coli vs. Shigella flexneri: how different patterns of gene expression affect virulence. FEMS Microbiol Lett 301: 156-163.

Moreno AC, Filho AF, Gomes T do A, Ramos ST, Montemor LP, Tavares VC, Filho L do S, Irino K, Martinez MB 2010. Etiology of childhood diarrhea in the northeast of Brazil: significant emergent diarrheal pathogens. Diagn Microbiol Infect Dis 66: 50-57.
Navarre WW, Zychlinsky A 2000. Pathogen-induced apoptosis of macrophages: a common end for different pathogenic strategies. Cell Microbiol 2: 265-273.

Nonaka T, Kuwabara T, Mimuro H, Kuwae A, Imajoh-Ohmi S 2003. Shigella-induced necrosis and apoptosis of U937 cells and J774 macrophages. Microbiology 149: 2513-2527.

Parsot C, Ageron E, Penno C, Mavris M, Jamoussi K, d'Hauteville H, Sansonetti P, Demers B 2005. A secreted anti-activator, OspD1, and its chaperone, Spa15, are involved in the control of transcription by the type III secretion apparatus activity in Shigella flexneri. Mol Microbiol 56: 1627-1635.

Petri WA Jr, Miller M, Binder HJ, Levine MM, Dillingham R, Guerrant RL 2008. Enteric infections, diarrhea and their impact on function and development. J Clin Invest 118: 1277-1290.

Sansonetti PJ 1991. Genetic and molecular basis of epithelial cell invasion by Shigella species. Rev Infect Dis 13 (Suppl. 4): 285-292.

Sansonetti PJ, Arondel J, Cantey JR, Prévost MC, Huerre M 1996. Infection of rabbit Peyer's patches by Shigella flexneri: effect of adhesive or invasive bacterial phenotypes on follicle-associated epithelium. Infect Immun 64: 2752-2764.

Sansonetti PJ, Kopecko DJ, Formal SB 1982. Involvement of a plasmid in the invasive ability of Shigella flexneri. Infect Immun 35: $852-860$.

Sansonetti PJ, Ryter A, Clerc P, Maurelli AT, Mounier J 1986. Multiplication of Shigella flexneri within HeLa cells: lysis of the phagocytic vacuole and plasmid-mediated contact hemolysis. Infect Immun 51: 461-469.

Schroeder GN, Hilbi H 2008. Molecular pathogenesis of Shigella spp: controlling host cell signaling, invasion and death by type III secretion. Clin Microbiol Rev 21: 134-156.

Silva RM, Toledo MR, Trabulsi LR 1980. Biochemical and cultural characteristics of invasive Escherichia coli. J Clin Microbiol 11: 441-444.

Silva RM, Toledo MR, Trabulsi LR 1982. Correlation of invasiveness with plasmid in enteroinvasive strains of Escherichia coli. J Infect Dis 146: 706.

Suzuki T, Franchi L, Toma C, Ashida H, Ogawa M, Yoshikawa Y, Mimuro H, Inohara N, Sasakawa C, Nuñez G 2007. Differential regulation of caspase-1 activation, pyroptosis and autophagy via Ipaf and ASC in Shigella-infected macrophages. PLoS Pathog 3: e111.

Trabulsi LR, Fernandes MR, Zuliani ME 1967. Novas bactérias patogênicas para o intestino do homem. Rev Inst Med Trop Sao Paulo 9: 31-39.

Venkatesan MM, Goldberg MB, Rose DJ, Grotbeck EJ, Burland V, Blattner FR 2001. Complete DNA sequence and analysis of the large virulence plasmid of Shigella flexneri. Infect Immun 69: 3271-3285.

Zychlinsky A, Kenny B, Ménard R, Prévost MC, Holland IB, Sansonetti PJ 1994. IpaB mediates macrophage apoptosis induced by Shigella flexneri. Mol Microbiol 11: 619-627.

Zychlinsky A, Prevost MC, Sansonetti PJ 1992. Shigella flexneri induces apoptosis in infected macrophages. Nature 358: 167-168.

Zychlinsky A, Thirumalai K, Arondel J, Cantey JR, Aliprantis AO, Sansonetti PJ 1996. In vivo apoptosis in Shigella flexneri infections. Infect Immun 64: 5357-5365. 